\title{
Tornadoes over complex terrain: An analysis of the 28th August 1999 tornadic event in eastern Spain
}

\author{
${ }^{1}$ V. Homar, ${ }^{2}$ M. Gayà, ${ }^{1}$ R. Romero, ${ }^{1}$ C. Ramis, and ${ }^{1,3}$ S. Alonso \\ ${ }^{1}$ Meteorology Group, Dept. de Física, Univ. de les Illes Balears, Palma de Mallorca, \\ Spain \\ ${ }^{2}$ Instituto Nacional de Meteorología, Centre Meteorològic a les Illes Balears, Palma de \\ Mallorca, Spain \\ ${ }^{3}$ IMEDEA, UIB-CSIC, Palma de Mallorca, Spain
}

Manuscript submitted to

Atmospheric Research. Special Issue ECSS 2002

October 22, 2002

Offset requests to:

V. Homar

Departament de Física

Universitat de les Illes Balears

07071 Palma de Mallorca, Spain

victor.homar@uib.es 


\begin{abstract}
On 28 August 1999, a tornadic storm developed during the afternoon over the Gudar range, near the border between Teruel and Castellón provinces (Sistema Ibérico, eastern Spain). The area has a characteristic complex terrain with peaks up to 2000 $\mathrm{m}$. At least one tornado developed which attained F3 intensity, producing severe damage in the forest that covers the mountains. The region is well known as a summer convective storm nest and, not surprisengly, a range in the Sistema Iberico is called Sierra del Rayo (lightning range).

The meteorological situation on 28 August 1999 shows the presence of a thermal low over the Iberian peninsula, producing warm and moist air advection towards inland Castellon at low levels. Meanwhile, a cold trough crossed the Iberian Peninsula from west to east at upper levels. Deep convection is identified on the Meteosat images during the afternoon, when the upper level trough reached the area where warm and humid mediterranean air was concentrated. The radar images reveal signals indicating the supercellular character of the tornado-producing storm. Weak echo region, frontal and rear inflow notches are identified on the low-level CAPPIs images.

In order to study the roles of the orography and the solar radiation on the ingredients associated with the tornadic storm development, numerical simulations of the event were performed, using the non-hydrostatic MM5 model. Very fine grid resolution, up to $2 \mathrm{~km}$ in the horizontal, allows us to determine the role of the complex terrain in favouring environmental conditions associated with the onset of severe convection. In fact, interaction of certain low-level flows with particular topographic features with scales of about 20 to $50 \mathrm{~km}$ is found to generate intense small-scale circulations over the storm nesting region. A more detailed analysis of the orographic effect shows that fine scale terrain features $(2-5 \mathrm{~km})$ are responsible for the intensification of the convective storms, whereas modification of the low-level flow by the large scale features $(20-50 \mathrm{~km})$ is able to trigger the convective systems. The effect of the solar-induced surface heating is also analysed and it turns to be crucial not only by intensifying the Iberian thermal low and the easterly warm and moist air advection towards the area but also by promoting mountain breezes.
\end{abstract}

Correspondence to: V. Homar 


\section{Introduction}

Severe weather occurs frequently in summer and autumn over the eastern part of the Iberian Peninsula (see Fig. 1 for the locations referred to in the text). Most of these cases are related to deep moist convection, normaly promoted by mesoscale warm air inflows at low levels (typically moistened over the Mediterranean sea) and a synoptic scale cold system at mid-levels (typically an eastward moving Atlantic trough). Then, subsynoptic scale features are usually the responsible for triggering the convection at particular places. As a result of the deep moist convection, heavy precipitation events are frequent on the area, with amounts exceeding $400 \mathrm{~mm}$ in $24 \mathrm{~h}$ in some cases (Homar et al., 1999; Romero et al., 2000). Hail is the most devastating threaten for the agricultural economy of northeastern Spain. Moreover, strong convection in eastern Spain sometimes produces tornadoes and waterspouts. For instance, Gayà et al. (2001) present a descriptive climatological study of the tornadoes and waterspouts in the Balearic Islands. They characterize 54 waterspouts and 27 tornadoes reported in 11 years, with intensities from F0 to F3 in the Fujita (1981) scale.

Previous works have analysed the synoptic and mesoscale aspects of tornado cases in eastern Spain. Ramis et al. $(1997,1999)$ present a detailed observational analysis of a tornado event over north-eastern Spain, produced by a rapidly growing convective system. A F2 tornado affected the city of Sigüenza, central Spain, on May 1993 and was described in detail by Martín et al. (1995) by using surface data, satellite and radar imagery.

The case presented here occurred in the afternoon of 28 August 1999 over the Sistema Iberico. This region is particularly active during summer and beginning of autumn with regard to convection developments. In fact, the number of summer stormy days presents a maximum over this topographic system, with an average of more than 12 days with a reported storm per summer. In the same way, the area is characterized by frequent lightning. Figure 2 shows that, during the period 1998-2001, more than 800 strokes per year are detected at the maximum found over the Sistema Ibérico, being the region with the highest lightning activity in northeastern Spain, together with the Pyrenees and the Catalonian coastal lands. On account of this, and as a proof of this important lightning activity, the population of the area has named a certain range Sierra del Rayo (the Lightning Range). The Pyrenees signal stems from the summer daytime storms, whereas the signal along the Catalonian coast is a clear evidence of the importance of the sea breeze in triggering convection along the coastal areas. The frequent convective activity in the low-populated Sistema Iberico area suggests that the tornado occurrences are likely much higher than actually reported. 
It is interesting to note that another tornado was reported in 1992 with its track crossing the one followed by the tornado presented in this study.

Figure 3 shows the complex terrain that shapes the Sistema Iberico. Heights in the area range from the sea level, just $50 \mathrm{~km}$ from the tornado track, to a maximum height of $2023 \mathrm{~m}$. The tornado track was estimated from survey of the damage by one of the authors (Gayà). The track was $18.5 \mathrm{~km}$ long, and about $17 \mathrm{~km}$ straight distance from the touchdown to the liftoff locations (Fig. 3). The touchdown occurred in a valley at a height of $1400 \mathrm{~m}$. A direct observer brought out that the approximated time for the touchdown was at 1745 UTC and that it lasted for more than 15 minutes. The tornado surmounted highlands exceeding $1750 \mathrm{~m}$ and, by the end of its trajectory crossed low lands at a height of less than $1200 \mathrm{~m}$. The intensity of the wind along its path was estimated from the forest damage and ranged from F0 to F3, reaching its maximum intensity at about $1 / 3$ of the track.

The aim of this study is the analysis of the meteorological conditions in which the tornado developed and the determination of the orographic effect on the generation of environments favorable for convection and mesocyclones. By performing numerical sensitivity experiments we try to determine the role played by the complex terrain on the generation of the potentially tornadic mesocyclone in the model simulations. First, in section 2, an observational overview shows the synoptic and mesoscale aspects of the environment in which the tornado-producing mesocyclone developed. Radar images showing the vertical and horizontal structure of the convective system are analysed. In section 3 details about the numerical experiments configuration and the control simulation results are presented. Sensitivity experiments dealing with multiscale orographic aspects and the solar radiation role are discussed in section 4. Conclusions and final remarks are presented in 5 .

\section{Observations}

An overview of the available observations of the event is presented, including the National Center for Environmental Prediction (NCEP) analyses, Meteosat satellite and radar images.

The synoptic situation in which the event developed is dominated by a weak but notably cold trough at mid and upper levels crossing north Spain, which produced westerlies to north-westerlies during the second half of August 28 over northeastern Spain (Fig. 4a,b). At low levels, warm air is located over the Iberian peninsula and Westerm Mediterranean, and a thermal low is well developed at 1200 UTC over Spain, producing warm and moist easterly flow all along northeastern 
Spain during the afternoon (Fig. 4c,d). Note that over the Sistema Ibérico, at mid and upper-levels westerly wind increases during the afternoon, while at low levels the easterly wind is consistently strengthened as the surface low is shifted to the southeast, producing both an increase, at least at synoptic scale, of the low-tropospheric shear over the region.

In this kind of scenarios, convection is very common over northeastern Spain. For this case, Meteosat infrared image at 1800 UTC shows convective developments over the Pyrenees, Catalonia coastline and an incipient nucleus triggered over the Sistema Ibérico (Fig. 5a). This particular convective development, which moved to the east steered by the mid-levels flow, splitted in two cells (clearly identifiable at 1830 UTC, Fig. 5b) and was the system which generated the tornado. The quick development, as well as its later split are evidences of convective severity and signals for potential hazardous weather (Lemon, 1980; Falk, 1997). A more detailed analysis of the structure of this cell can be done using the radar images. Unfortunately the images from the closest radar located in Valencia are not available. The only available images are from the Zaragoza radar, located $140 \mathrm{~km}$ north from the convective cell (Fig. 6) and at height of $819 \mathrm{~m}$ above sea level. The CAPPI at $2.8 \mathrm{~km}$ at 1800 UTC shows active nuclei over eastern Pyrenees and the isolated tornadogenetic cell developed over the administrative boundary between Castellon and Teruel (compare with the tornado track estimation in Fig. 3). A closer view of the cell at different levels reveals clear signals of strong updrafts and vertical shear in the cell (Fig. 7). Note that though not visible on the infrared meteosat images until 1830 UTC (Fig. 5a), the convective cell is already splitting at 1800 UTC, as clearly seen at all levels in Fig. 7. South and east notches notably marked at $2.8 \mathrm{~km}$ suggest the existence of warm and moist inflow feeding the storms. Rear inflow is more evident from the northwest at 5.5 and $7.5 \mathrm{~km}$, in good agreement with the westerly synoptic flow shown in the NCEP analyses (Fig. 4). This confirms the existence of strong vertical shear, so favouring the cell split along the wind direction. In addition, a clear weak eacho region is identifiable to the south of the system, confirming also the high shear present at low and mid levels. The superposition of the estimated tornado track on the radar data suggests that the southern cell, right hand side from the steering flow, was the responsible for the tornadogenesis, though whether the tornado was generated before, during or after the cell split remains unclear.In addition, being certainly a tornadogenetic storm, no firm evidences are found either about the supercell character of the convective development or about a mesocyclone formation.

Once the observational data available for this case have been analyzed, we present a numerical study trying to determine the mechanisms responsible for the severe convection environment, paying special attention to the orographic effect, as a possible general explanation of the high storm 
frequency of the area.

\section{Control Simulation}

\subsection{Model configuration and control experiment description}

Numerical experiments were performed using the $5^{\text {th }}$ generation of the Pennsylvania State University-National Center for Atmospheric Research Mesoscale Model (MM5v3, Dudhia, 1993; Grell et al., 1995).

The MM5v3 is a full non-hydrostatic model formulated using a Lambert conformal map projection in the horizontal and the terrain-following $\sigma$-coordinate system in the vertical. The multiplenest capability of the model has been used in order to capture both the synoptic-scale evolution and the mesoscale features (up to the convective scale) of the episode with manageable computational cost. Three domains of $151 \times 151$ grid points were used to cover the wide range of scales of interest in this study (Fig. 8). The coarsest domain, with $18 \mathrm{~km}$ resolution, measures $2700 \mathrm{~km}$ $\times 2700 \mathrm{~km}$ and covers western Europe, North Africa and the north-western Atlantic ocean. This domain is used to capture the large-scale aspects of the event while not compromising the finest domain resolution. The second domain has $6 \mathrm{~km}$ grid size. It covers eastern Iberian Peninsula and the Balearic Islands in order to consistently capture the low levels eastern flow and the possible sea breeze regulation. A two way nesting strategy is used by this domain to interact with both the coarser and finer domains. The finest domain is centered over the Sistema Ibérico and extends $300 \mathrm{~km} \times 300 \mathrm{~km}$ with a $2 \mathrm{~km}$ horizontal grid spacing. The time steps used are $60 \mathrm{~s}, 20 \mathrm{~s}$ and about $7 \mathrm{~s}$ respectively. Initial and boundary conditions dataset for the coarse domain are constructed from the Global analyses of the National Center for Environmental Prediction (NCEP), available at 0000 UTC and 1200 UTC, which are reanalysed at the model resolution using surface and upper-air observations.

Referring to the time span covered by the experiments, since the tornado was reported to occur at about 1800 UTC and the coincidence of the upper-level cold trough passage and low-level easterly flow over northeastern Spain was during the afternoon, a 21-hour long simulation was performed: from 0000 to 2100 UTC August 28. The simulated time interval covers the scenario previous to the convection formation, so allowing the small scale circulations, mostly governed by the diurnal radiation, to be formed by that time.

The MM5v3 model includes different physical parameterizations. For the present study, the Kain and Fritsch (1990) convective parameterization scheme was used for domain 1 whereas ex- 
plicit resolved convection is expected at 6 and $2 \mathrm{~km}$ resolution of domains 2 and 3 respectively. Resolved-scale moist processes follow the mycrophysics scheme of Dudhia (1989), which allows for a simple representation of snow and cloud ice. The parameterization chosen to represent the planetary boundary layer subgrid processes is a modified version of the Blackadar scheme (Zhang and Anthes, 1982). It includes an implicit vertical diffusion scheme, assuming a k-profile and distinguishes between the so-called nocturnal (stable, mechanically driven turbulence and unstable forced convection cases) and the diurnal free convection PBL regimes. Sea level temperatures remain constant during the simulation and are taken from the NCEP weekly analysis. A sophisticated radiation scheme is used. It accounts for longwave and shortwave interactions with the model explicit clouds, clear air and precipitation (Benjamin, 1983).

\subsection{Model Validation}

The numerical sensitivity study intended in next section requires obtaining a control run which reproduces, to some extent, the observed meteorological features under study. In the case of tornadogenesis, it is still far from the current numerical tools (even at grid resolutions much higher than the used here) to reproduce tornadic circulations from observational data. However, it is nowadays reasonable to expect from the models to reproduce an environment with sufficient ingredients to develop tornado-generating storms, i.e. severe convection and intense mesocyclones. For the present study, the control run appears to be reproducing such ingredients with enough spatial and temporal accuracy to be considered for further diagnosis and numerical experimentation. In fact the control run is considered as an exceptional run since it succesfully reproduces explicit convective activity over the Pyrenees and Sistema Ibérico and in particular, it reproduces mesocyclonic circulations close the tornado location and about at the same time (1730 UTC, Fig. 9). This does not obviously mean that the model has exactly reproduced the actual mesoscale evolution during August 28, but it shows that the environment and ingredients which lead to the severe convective development appear to be well captured in the simulation.

The mesocyclone identified on Fig. 9 at $500 \mathrm{hPa}$ at 1730 UTC has an approximate diameter of $15 \mathrm{~km}$ and it has two accompanying strong updrafts at its eastern and western flanks. This supports the idea that the model has reproduced strong updrafts together with small mesocyclones, interpreted as systems elegible for potential tornadogenesis.

As an objective tool for identifying those systems in the simulations we use a parameter STORM 
defined as:

$S T O R M=\delta w \quad$ for $\quad w \geq 5 \mathrm{~ms}^{-1}$ and $\delta \geq 10^{-3} \mathrm{~s}^{-1}$ at 5 isobaric levels $(\triangle p=50 \mathrm{hPa})$

and $\mathrm{STORM}=0$ otherwise. Here, $w$ is the vertical velocity and $\delta$ the relative vorticity. This parameter is intended to identify strong updrafts associated to vertically consistent rotating systems with relative vorticity of the order of mesocyclones. Figure 10 shows the evolution of STORM, integrated across domain 3 (except the Pyrenean northern third) at the level of $550 \mathrm{hPa}$ (level of maximum response) for the control simulation. There are three clear periods when STORM activity is detected over the area, from 1500 to 1900 UTC. This is in a good agreement with the period of convective activity detectable on the series of radar images from Zaragoza (not shown).

Once the control run is validated, the numerical model becomes a good tool for sensitivity analysis of the mechanisms involved in the development of favourable environments for rotating storms.

\section{Sensitivity Experiments}

The effects of the orography and the shortwave radiative heating is determined by using classical sensitivity analysis. The differences between the control run and a simulation with one factor turned off are attributed to the action of that factor, which is naturally interacting with all the remaining modeled physical processes.

The first experiment performed in this study is a simulation with flat orography. This simulation contains no information about the orographic systems in the domain but that contained in the initial and boundary conditions, which are built from real data. Having into account that we focus our interest on systems which develop after 15 hours of simulation and on a $2^{\text {nd }}$ level of domain nesting, the orographic contribution in this flat orography simulation is assumed to be negligible. Results from the no orographic run show that, under a very similar synoptic situation, neither mesocyclone nor deep convective developments are simulated, and the STORM parameter results zero at all times. This means that no strong updrafts are found coexisting with vertically coherent rotation when the low-level flow is not perturbed by the orography. This allows to attribute a primary role to the orography in generating the favorable environment for mesocyclone generating storms.

We now focus the attention on the role of the small scale components, or complexity of the orography. Thus, we configure a simulation with a smoothed orography by using a $20 \mathrm{~km}$ resolu- 
tion orography (see Fig. 11) for the finest domain instead of the $2 \mathrm{~km}$ resolution one (see Fig. 12). The results from this simulation show a nearly identical synoptic and mesoscale situation than in the control run, which satisfies the STORM parameter criteria. Figure 10 shows important activity from 1400 to about 1830UTC, which is actually located over the Sistema Iberico. However, the control run renders larger values of STORM, so a first interpretation of the differences observed over Fig. 10 is that small scale orographic structures (more precisely, the structures not included in the $20 \mathrm{~km}$-grid orography) are responsible for the intensification of the mesocyclones. Note that this sensitivity technique does not reveal the physical mechanisms which link the small scale topography to that intensification process but it clearly states the existence of that link.

In addition to the utility of the smoothed orography run in determining the role of the small scale orographic features, the simulation has an added value since it shows very similar fields to the control run but with smoothed structures. This allows an easier analysis of the situation and the identification of a mechanism for the development of intense small cyclonic circulation with strong vertical updrafts in the area, as observed in the control run (Fig. 9). Figure 11 shows the mesoscale situation at low $(950$ and $800 \mathrm{hPa})$ and mid $(500 \mathrm{hPa})$ levels at $1300 \mathrm{UTC}$, time when the simulation is starting to show STORM activity (Fig. 10). At $950 \mathrm{hPa}$ the wind field shows a well developed sea breeze all along the coastal lands, as well as northwesterly wind channeled along the Ebro valley. The diffluent pattern identifiable on the wind across the Ebro valley would be an evidence of the mountain breezes due to an important heating on the mountain slopes. In fact, the temperature field at $800 \mathrm{hPa}$ (Fig. 11b, note the applied zoom over the area of interest) shows high temperature values over the Sistema Ibérico mountains, due to the high radiation, characteristic of the summer months.

The southwesterly general flow is notably perturbed by local effects. Note the important shear at low levels along the coastal lands and also the effect of the mountain breeze in veering the wind towards the slope direction. This could favour the meso-cyclogenesis by convergence under certain mountain ridge shapes. This can be seen on the closed circulation identifiable on Fig. 11b formed on the northwestern edge of the main range in the area. Finally, at upper levels, there is a general westerly flow produced by the synoptic cold trough and small scale perturbations on the temperature field, produced by incipient convective cells in the simulation.

Therefore, large scale $(20-50 \mathrm{~km})$ orography has two clearly identifiable effects, first is the low levels flow direct modification and second is the upslope wind veering due to mountain breeze development. Both effects can contributte under certain orographic structures to increase the wind shear and favour the severity of the convection. 
In order to confirm the important role of the solar radiation, an experiment with no solar radiative heating is conducted. This experiment is designed with the full $2 \mathrm{~km}$ orography but the solar constant is set to zero and so the night time lasts for the entire run. Results for this experiment confirm the important effect of the radiative heating in developing the active systems. No STORM parameter criteria is attained over the area of interest during the entire run and, as shown in Fig. 10, only at the latter hours of simulationsome notable systems develop over the sea as a consequence of the excessive land cooling and the long lasting night land breeze. As an evidence of the crucial role played by the radiation in modifying the low-level wind field, the equivalent figure to Fig. $11 \mathrm{~b}$ for the non radiation run is shown in Fig. 12. The temperature field is clearly not linked to topographically related heating and, consequently the wind field does not show deviations from the general southwesterly flow. If the differences in the orography used (full $2 \mathrm{~km}$ for the no solar radiation run) are not considered, the changes observed in Fig. 12 relative to Fig. 9 are completely atributable to the solar radiation.

Therefore, the joint action of the mid-scale $(20-100 \mathrm{~km})$ orography and the solar radiation emerges as a crucial contributor in generating the favourable environments for developing rotating storms in the area.

\section{Conclusions}

The study of a tornadic event occurred over the Sistema Ibérico (Spain) during the afternoon of 28 August 1999 has been presented. The area where this tornadogenetic storm developed is particularly active during summer in convection and lightning activity with more than 800 strokes per year. The tornado track and the tornado intensity could be well determined from forest damage. The tornado intensity ranged from F0 to F3. It lasted for about 15 min. and its path was $18.5 \mathrm{~km}$ long, beginning in a valley at a height of about $1400 \mathrm{~m}$. Then it crossed complex terrain with heights exceeding $1750 \mathrm{~m}$. This evidences that significant tornados are likely to occur even over areas with complex topography, where small scale rotation is maintained over strong slopes.

A preliminar observational overview of the event is shown before proceeding with the numerical sensitivity analysis. The synoptic situation over southwestern Europe on August 281999 at mid and upper levels was characterized by a cold trough crossing north Spain and south France towards the east, producing westerly flow over northeastern Spain. At low levels, warm air and an associated thermal low are detected over the Iberian Peninsula, producing moist easterly winds over the Sistema Ibérico area. This configuration is described to favour severe convective devel- 
opments since it provides convective instability and strong windshear. Meteosat imagery show the development of an isolated deep system with strong updrafts over the Sistema Iberico at 1800 UTC, which later splits into two cells. A closer view to this system using images from the radar in Zaragoza shows signals of severity. A weak echo region as well as frontal and rear inflow notches suggest that notable shear was present at low levels and reveal that moist and warm southeasterly flow was feeding the storm at low levels.

The role played by the multiscale features of the orography and by the solar radiation in favouring the severe event have been investigated by means of numerical sensitivity analyses. The nesting capability of the MM5 model has been used to run a simulation ranging from a $18 \mathrm{~km}$ grid size domain, covering Western Europe and North Africa, to a $2 \mathrm{~km}$ resolution domain which was intended to account for the finer scale features of the event over the Sistema Ibérico. The control run is described as a very accurate run since it reproduces the development of a mesocyclone with strong updrafts at about the tornado location and time. This allows a further sensitivity study in which the contribution of the orography and the solar radiation for the generation of the tornado-supporting environment in the simulation is determined. Both the orography and the solar radiation are shown to have a primary role in the development of the favourable environment. The synergistic action of the two considered factors appears as an important agent by generating mountain breezes which create particular small scale eddies under certain topographic shapes. Focusing on the role of the terrain elevation, the small scale $(2-5 \mathrm{~km})$ features of the orography emerge as strengtheners of the mesoscale eddies and vertical updrafts. However, large scale $(20-50 \mathrm{~km})$ aspects of the orography are able to trigger the convection and to perturb the low levels flow to force the generation of small scale cyclonic circulation.

These results, though derived from a single case study, give a useful guidance to a more general future investigation of the factors which explain the high frequency of severe convective storms over this particular region.

Acknowledgements. This research was mainly developed in the framework of the WMO-WWRP "Mediterranean Experiment MEDEX" project. Satellite images and precipitation data were provided by the Instituto Nacional de Meteorología (INM) of Spain. Computer support provided by NCAR/Scientific Computer Division (which is sponsored by the National Science Foundation) for model data preprocessing is also acknowledged. The authors especially aknowledge Nicolas Tena, a witness of the tornado which, together with Primitivo Dauden, helped us during the survey. The authors thank M. A. Heredia, J. Gonzàlez and P. Fernàndez for their help in providing us with satellite images and lightning charts. This work has been partially supported by the CICYT CLI99-0269 and CICYT REN2002-03482 grants. 


\section{References}

Benjamin, S. G., Some effects of heating and topography on the regional severe storm environment, $\mathrm{Ph} . \mathrm{D}$. thesis, The Pennsylvania State University, 265 pp. [Available from University Microfil, 300 N. Zeeb Rd., P.O. Box 1346, Ann Arbor, MI 46801-1346.], 1983.

Dudhia, J., Numerical study of convection observed during the winter monsoon experiment using a mesoscale two-dimensional model., J. Atmos. Sci., 46, 3077-3107, 1989.

Dudhia, J., A nonhydrostatic version of the Penn State/NCAR mesoscale model: Validation tests and simulation of an atlantic cyclone and cold front, Mon. Wea. Rev., 121, 1493-1513, 1993.

Falk, K., Techniques for issuing severe thunderstorm warnings with the WSR-88D Doppler radar, NOAA Technical Memorandum. SR-185, 1997.

Fujita, T. T., Tornadoes and downburst in the context of generailzed planetary scales, J. Atmos. Sci, 38, $1511-1534,1981$.

Gayà, M., Homar, V., Romero, R., and Ramis, C., Tornadoes and waterspouts in the balearic islands: phenomena and environment characterization, Atmospheric Research, 56, 253-267, 2001.

Grell, G. A., Dudhia, J., and Stauffer, D. R., A description of the fifth-generation Penn State/NCAR mesoscale model (MM5), NCAR Tech. Note NCAR/TN-398+STR, 1995.

Homar, V., Ramis, C., Romero, R., Alonso, S., García-Moya, J., and Alarcón, M., A case of convection development over the western Mediterranean sea: A study through numerical simulations, Meteor. Atmos. Phys., 71, 169-188, 1999.

Kain, J. S. and Fritsch, J. M., A one-dimensional entraining/detraining plume model and its application in convective parameterization, J. Atmos. Sci., 47, 2784-2802, 1990.

Lemon, L., Severe thunderstorm radar identification techniques and warning criteria, NOAA Technical Memorandum. NWS NSSFC-3, 1980.

Martín, F., de Esteban, L., and Riosalido, R., The Sigüenza tornado, (in Spanish). Nota técnica no. 25. Instituto Nacional de Meteorología., Apartado 285, 28071 Madrid, 1995.

Ramis, C., Arús, J., López, J. L., and Mestre, A., Two cases of severe weather in catalonia (spain). an observational study, Meteorol. Appl., 4, 207-217, 1997.

Ramis, C., López, J. L., and Arús, J., Two cases of severe weather in catalonia (spain). a diagnostic study, Meteorol. Appl., 6, 11-27, 1999.

Romero, R., Doswell III, C. A., and Ramis, C., Mesoscale numerical study of two cases of long-lived quasistationary convective systems over eastern spain, Mon. Wea.Rev., 128, 3731-3751, 2000.

Zhang, D. L. and Anthes, R. A., A high-resolution model of the planetary boundary layer-sensitivity tests and comparisons with sesame-79 data., J. Appl. Meteor., 21, 1594-1609, 1982. 


\section{Figure Captions}

Fig. 1. The Western Mediterranean area. The map includes locations referred to in the text. Square with dashed line indicates the area covered by map in Fig. $3 \mathrm{a}$.

Fig. 2. Yearly average number of lightning strokes over northeastern Spain for the period 1998-2001.

Fig. 3. a) Tornado track and surrounding region. See Fig. 1 for geographical location of the zoomed area. Administrative boundaries are included for further reference. b) Terrain height profile followed by the tornado.

Fig. 4. NCEP analysis on 1200 UTC August 28 and 0000 UTC August 29. Upper pannels show geopotential height (m, solid) and temperature $\left({ }^{\circ} \mathrm{C}\right.$, dashed) at $500 \mathrm{hPa}$. Lower pannels show sea level pressure (hPa, solid) and temperature $\left({ }^{\circ} \mathrm{C}\right.$, dashed $)$ at $900 \mathrm{hPa}$.

Fig. 5. Meteosat infrared images enhanced using a color palette for temperatures between $(-54,-30){ }^{0} \mathrm{C}$ on 28 August at a) 1800 UTC and b) 1830 UTC.

Fig. 6. CAPPI at $2.8 \mathrm{~km}$ from the radar in Zaragoza at 1800 UTC.

Fig. 7. CAPPIs at $2.8,5.5$ and $7.5 \mathrm{~km}$ from the radar in Zaragoza, zoomed over the tornadogenetic cell at 1800 UTC. Strong dashed line depicts the tornado track.

Fig. 8. Geographical area covered by the three model domains. Grid spacings and timesteps are shown for each domain and a star indicates the tornado location.

Fig. 9. Horizontal wind $\left(\mathrm{m} \mathrm{s}^{-1}\right)$ at $800 \mathrm{hPa}$ and upward velocity ( $\mathrm{cm} \mathrm{s}^{-1}$, shaded) at $500 \mathrm{hPa}$ for the control run at 1730 UTC. Contour interval is $300 \mathrm{~cm} / \mathrm{s}$. Areas with non-zero STORM parameter are bounded with strong solid line. A zoom over the area of interest is made to appreciate the full $2 \mathrm{~km}$ wind field details

Fig. 10. Evolution of the STORM parameter for the control (solid), no radiation (dashed) and smooth orography (dotted) simulations. Note that the no orographic simulation does not fullfil the STORM conditions at any time. 
Fig. 11. Mid and low levels mesoscale situation at 1300 UTC for the smoothed orography run. Horizontal wind $\left(\mathrm{m} \mathrm{s}^{-1}\right)$ and temperature $\left({ }^{\circ} \mathrm{C}\right)$ at a) $950 \mathrm{hPa}$, only above ground level. b) $800 \mathrm{hPa}$. c) $500 \mathrm{hPa}$. Note the larger zoom applied to panel $b$ than to panels a and $c$. Topography (100 $\mathrm{m}$ interval) as well as administrative boundaries are depicted for easy geographical reference.

Fig. 12. As in Fig. 11b but for the no solar radiation run. 


\section{Figures}

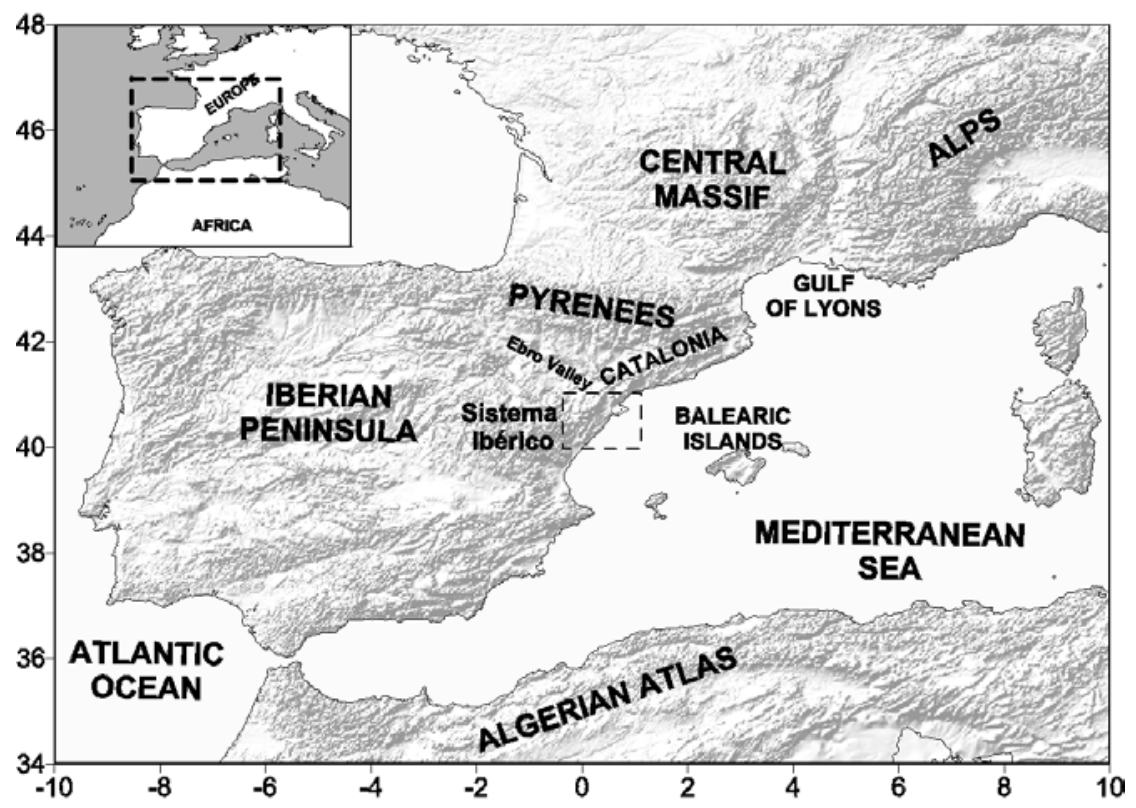

Fig. 1. The Western Mediterranean area. The map includes locations referred to in the text. Square with dashed line indicates the area covered by map in Fig. 3a.

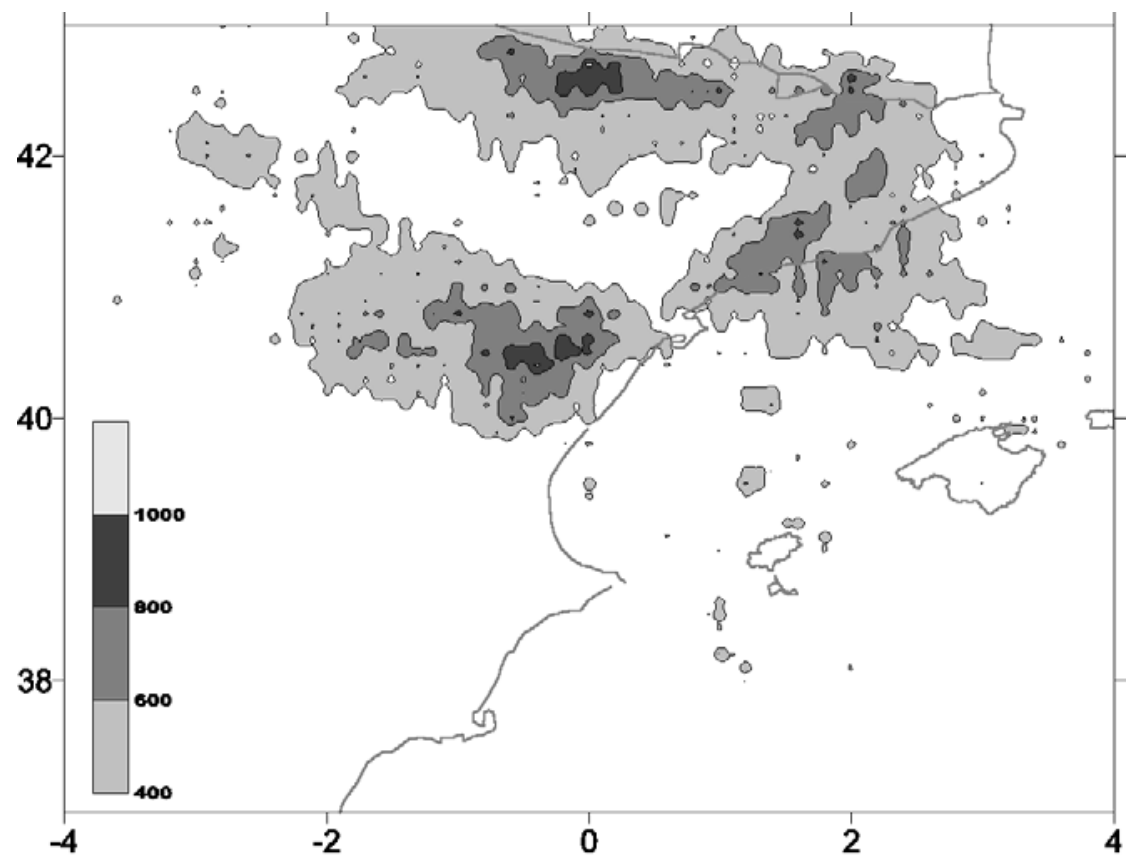

Fig. 2. Yearly average number of lightning strokes over northeastern Spain for the period 1998-2001. 

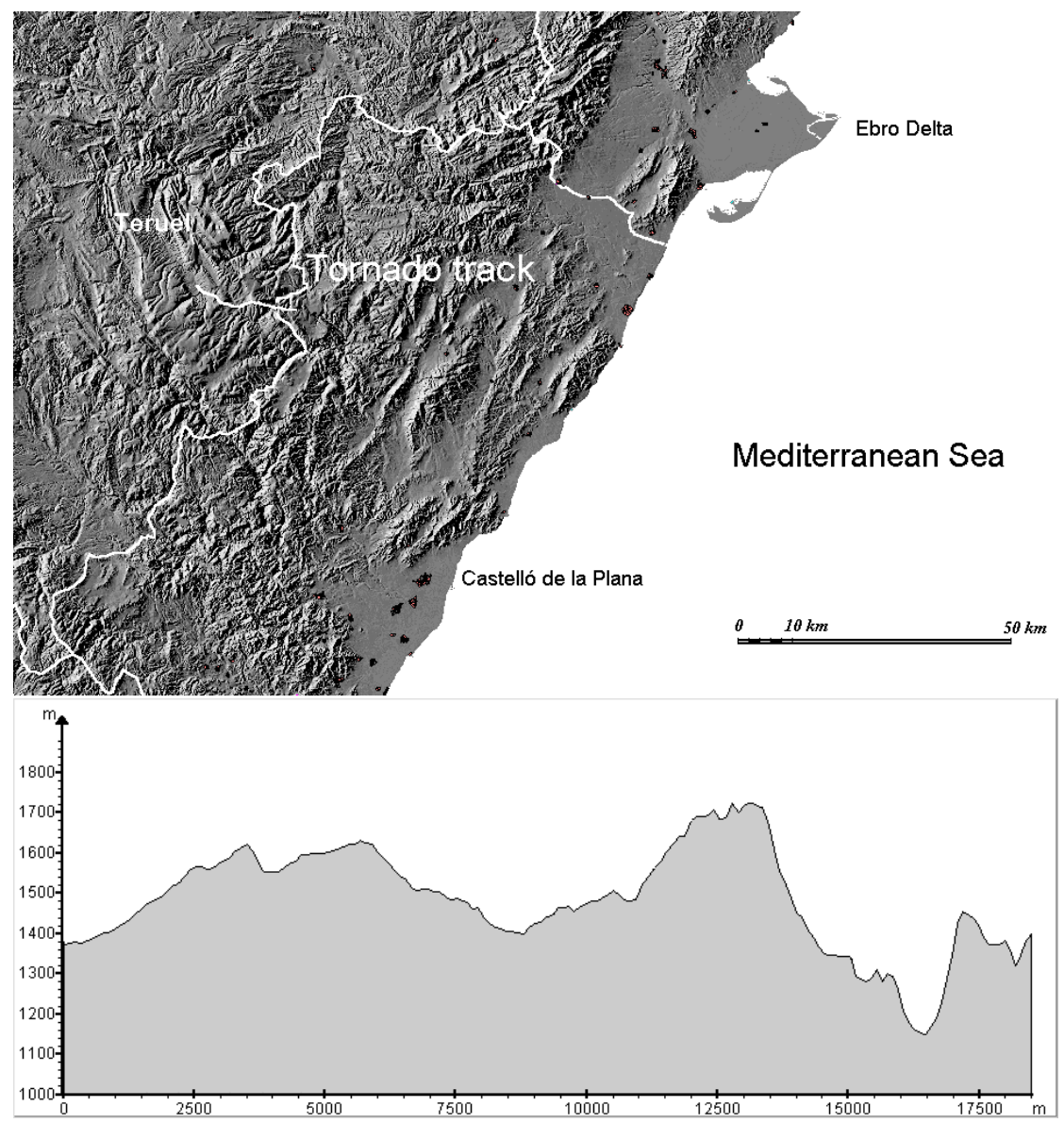

Fig. 3. a) Tornado track and surrounding region. See Fig. 1 for geographical location of the zoomed area. Administrative boundaries are included for further reference. b) Terrain height profile followed by the tornado. 


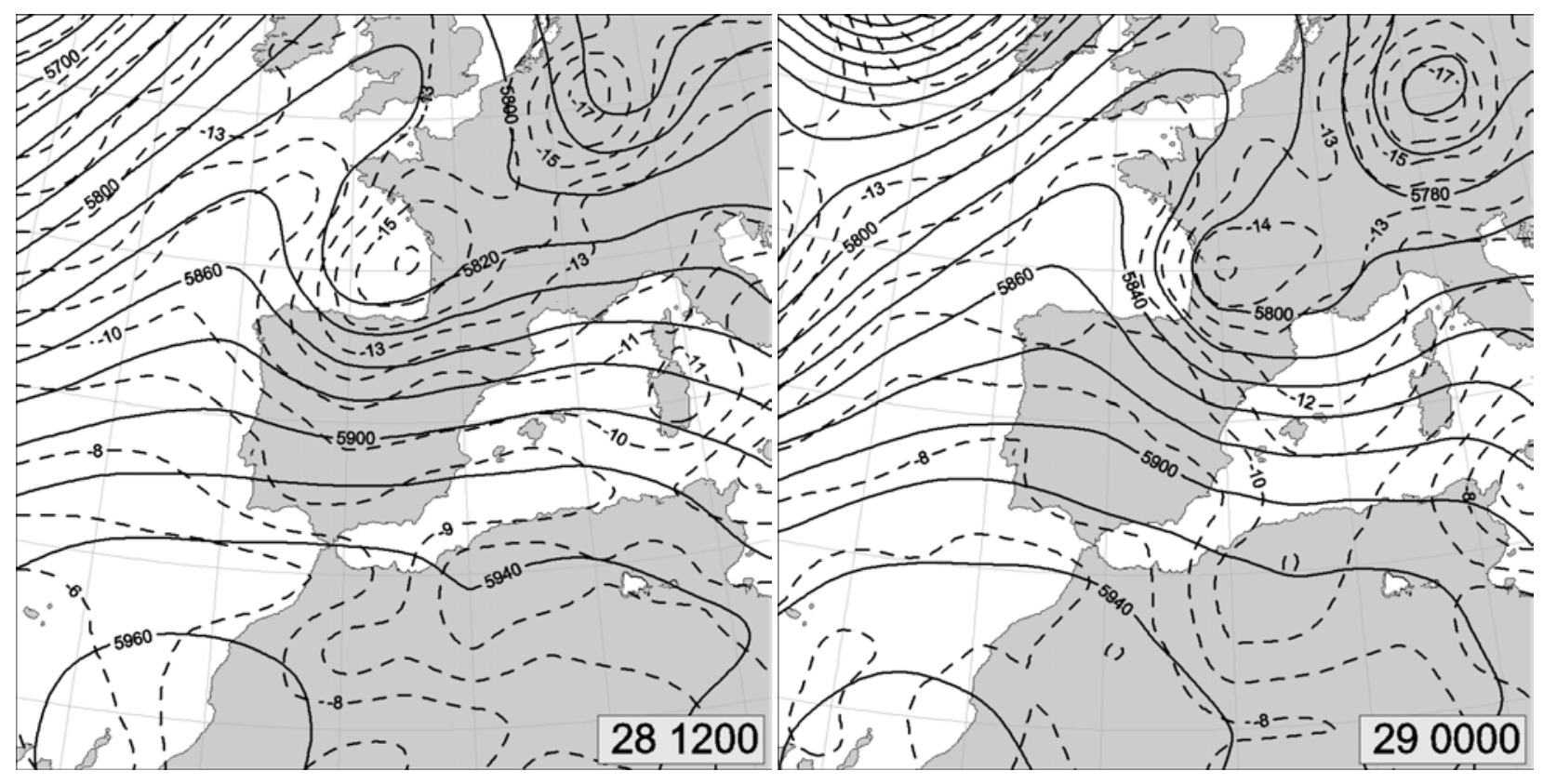

a

$\mathrm{b}$

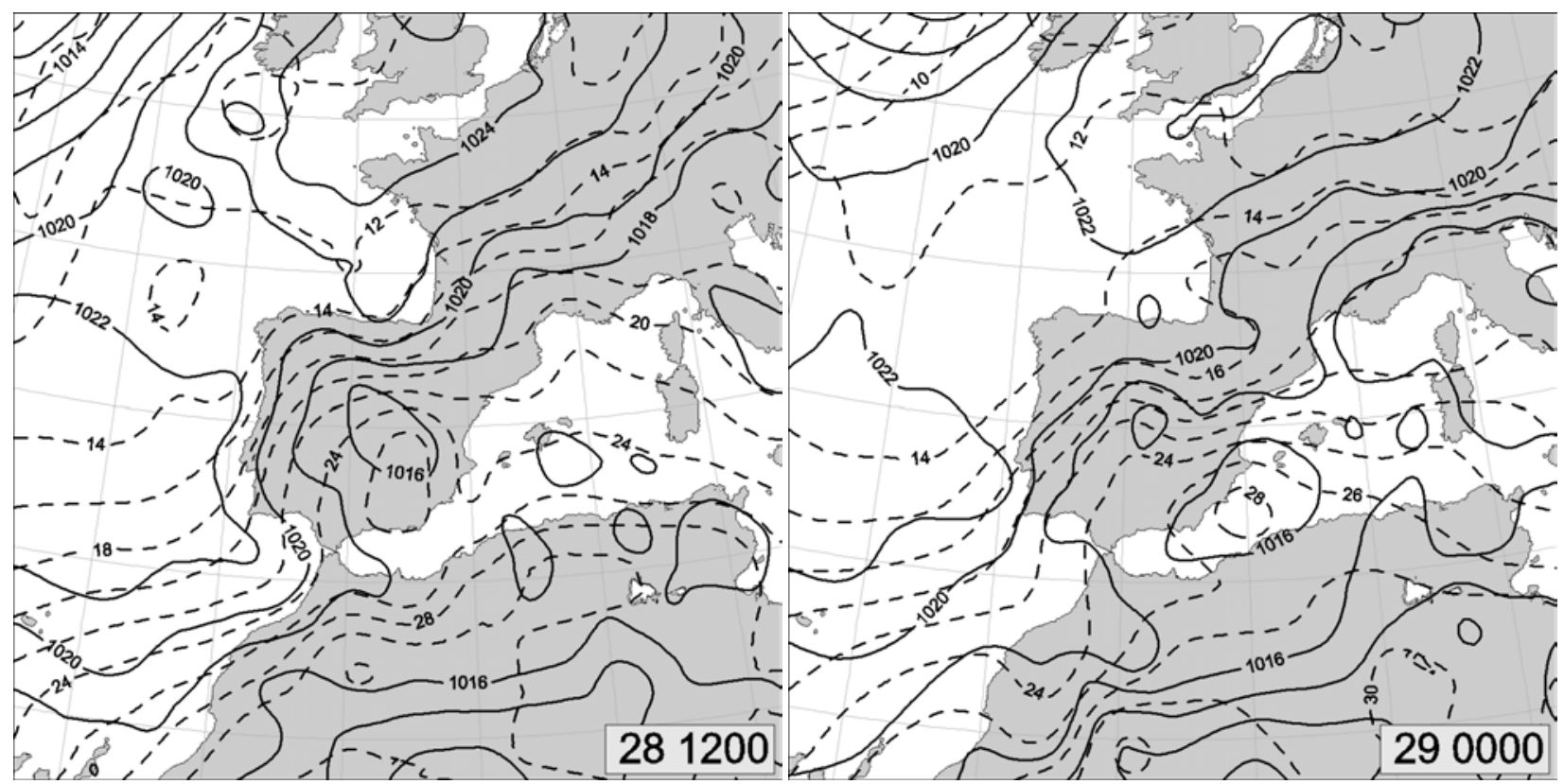

c

d

Fig. 4. NCEP analysis on 1200 UTC August 28 and 0000 UTC August 29. Upper pannels show geopotential height (m, solid) and temperature $\left({ }^{\circ} \mathrm{C}\right.$, dashed) at $500 \mathrm{hPa}$. Lower pannels show sea level pressure (hPa, solid) and temperature $\left({ }^{\circ} \mathrm{C}\right.$, dashed $)$ at $900 \mathrm{hPa}$. 


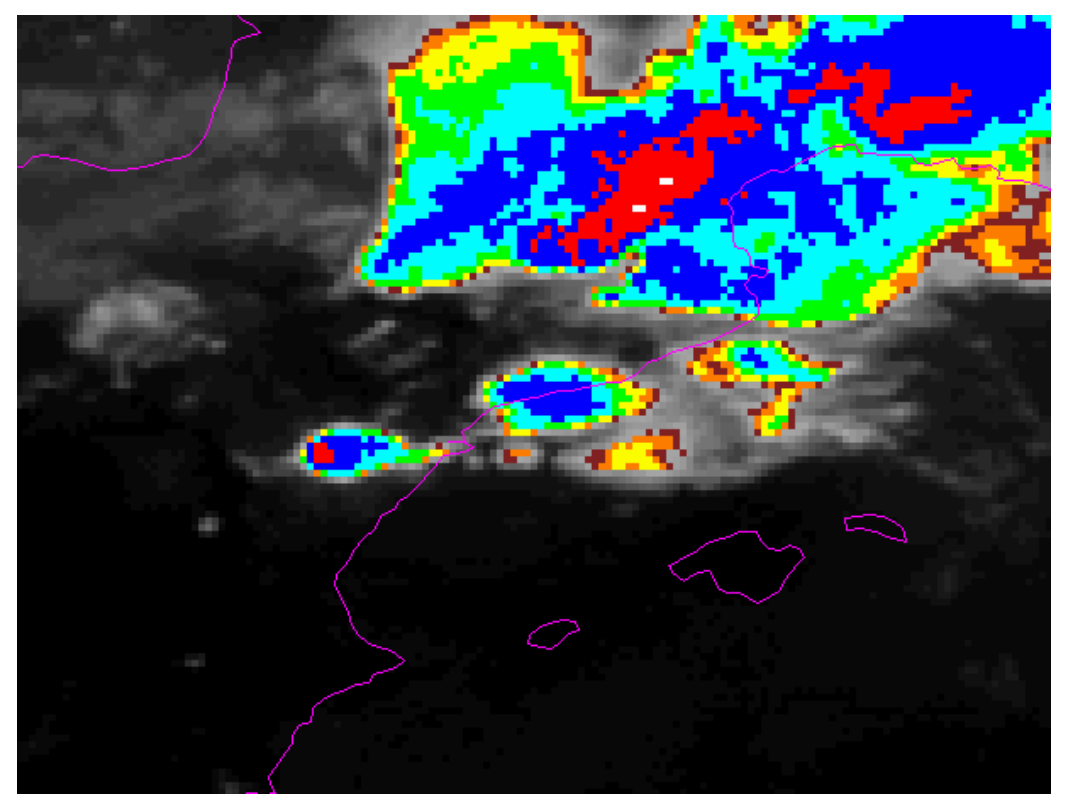

a

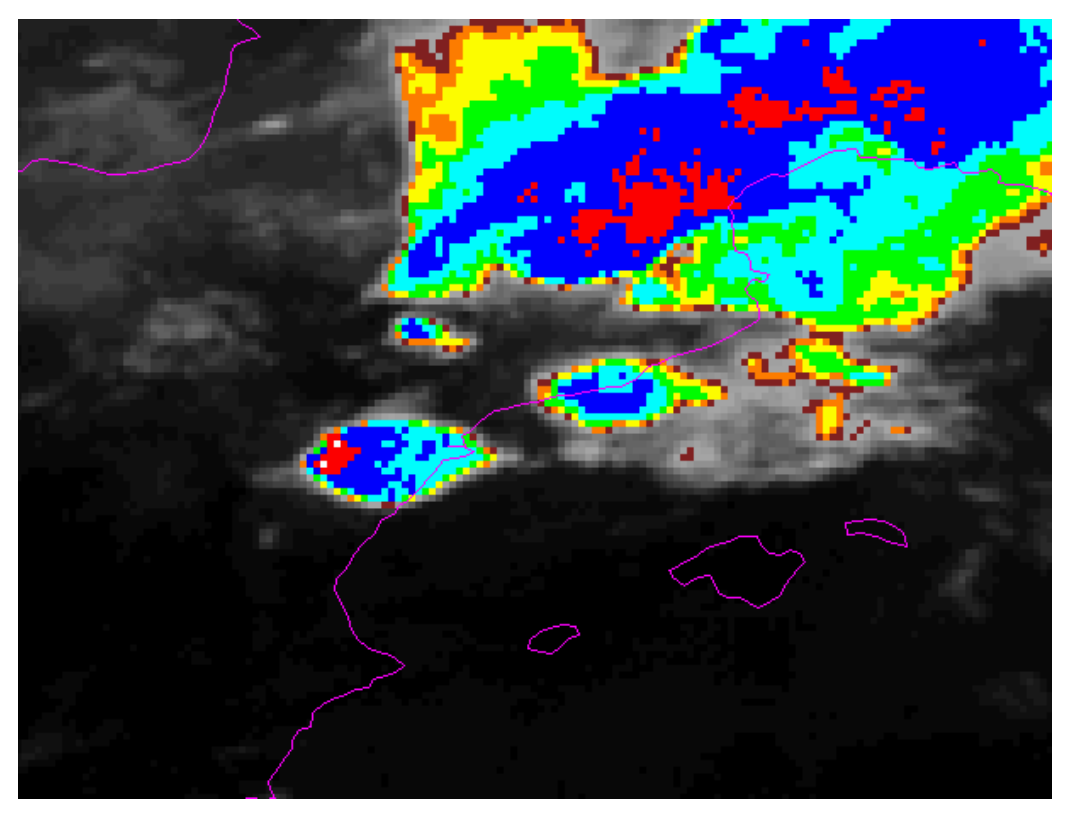

b

Fig. 5. Meteosat infrared images enhanced using a color palette for temperatures between $(-54,-30){ }^{0} \mathrm{C}$ on 28 August at a) 1800 UTC and b) 1830 UTC. 


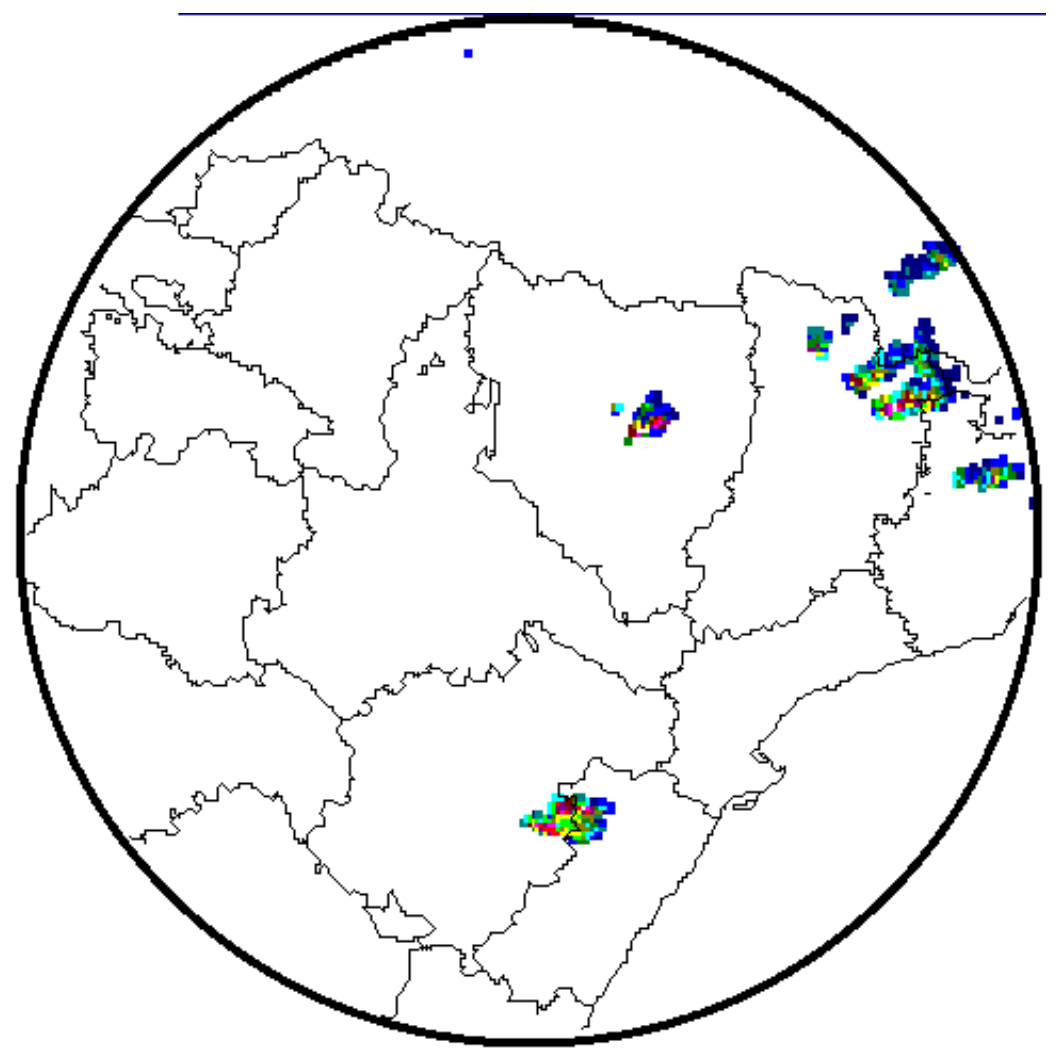

Fig. 6. CAPPI at $2.8 \mathrm{~km}$ from the radar in Zaragoza at $1800 \mathrm{UTC}$.

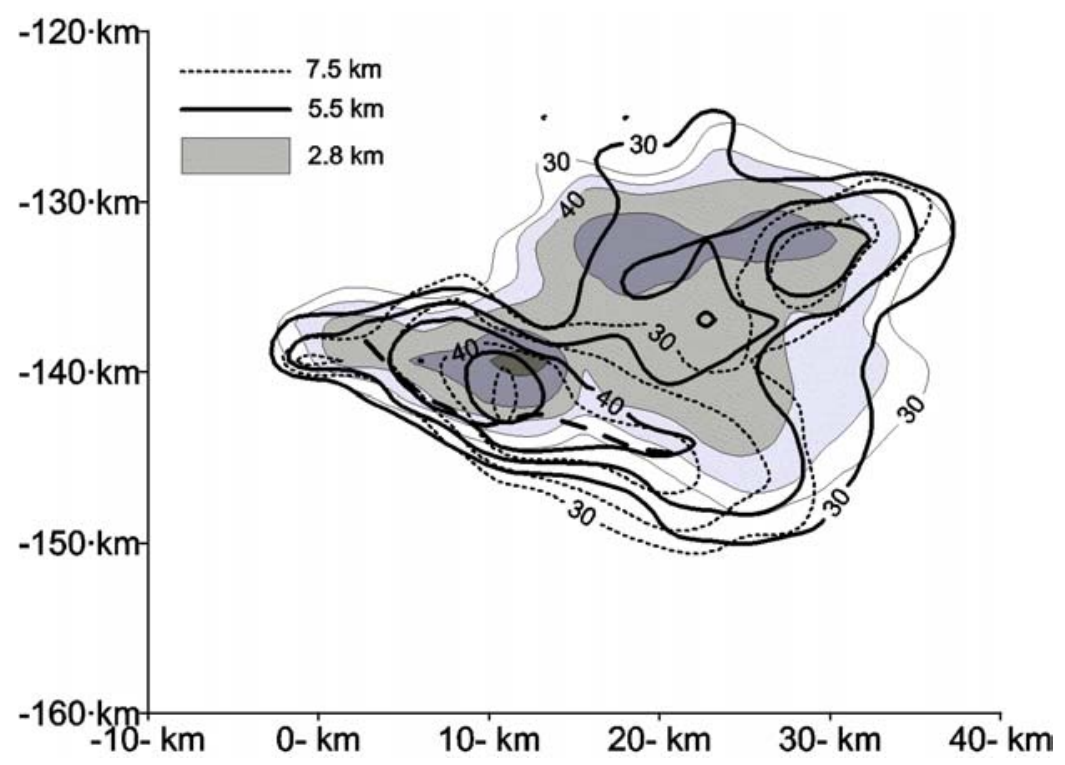

Fig. 7. CAPPIs at 2.8, 5.5 and $7.5 \mathrm{~km}$ from the radar in Zaragoza, zoomed over the tornadogenetic cell at 1800 UTC. Strong dashed line depicts the tornado track. 


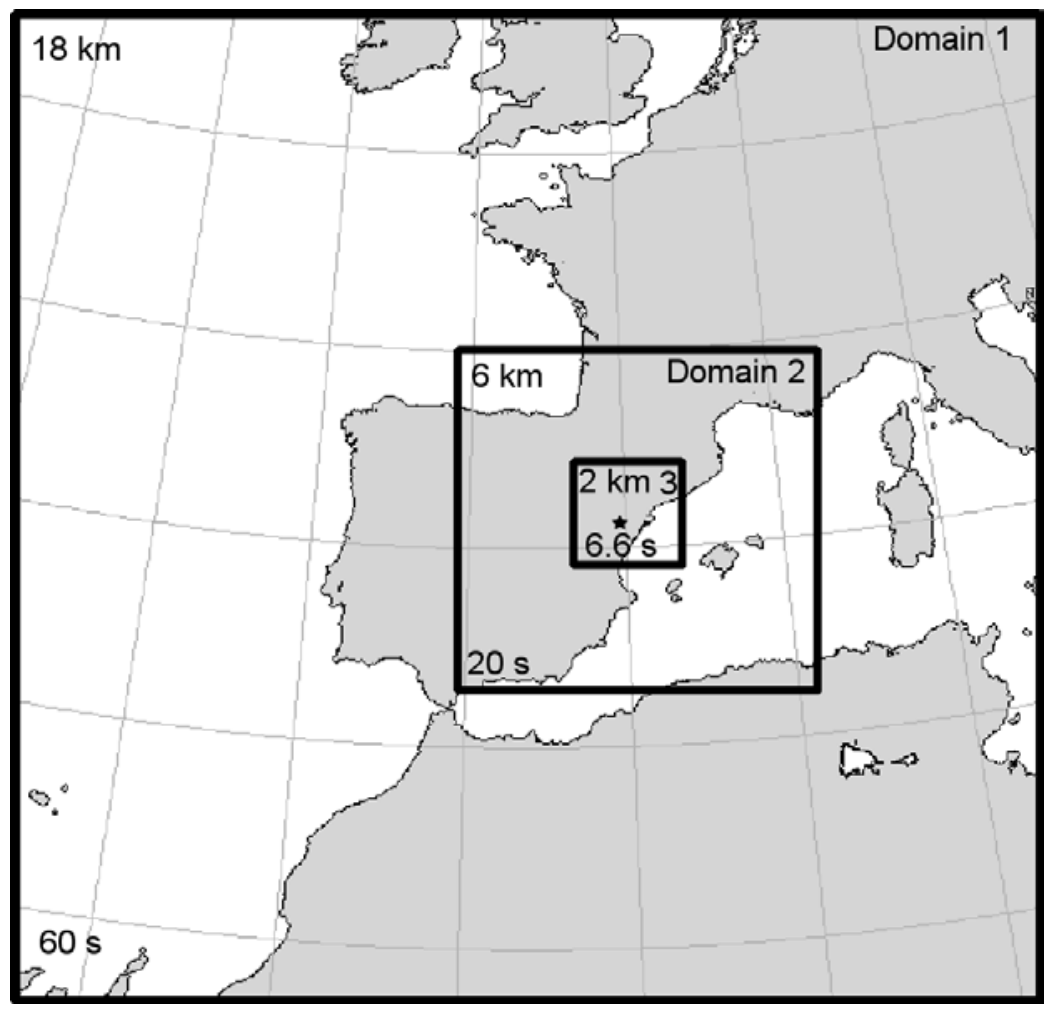

Fig. 8. Geographical area covered by the three model domains. Grid spacings and timesteps are shown for each domain and a star indicates the tornado location. 


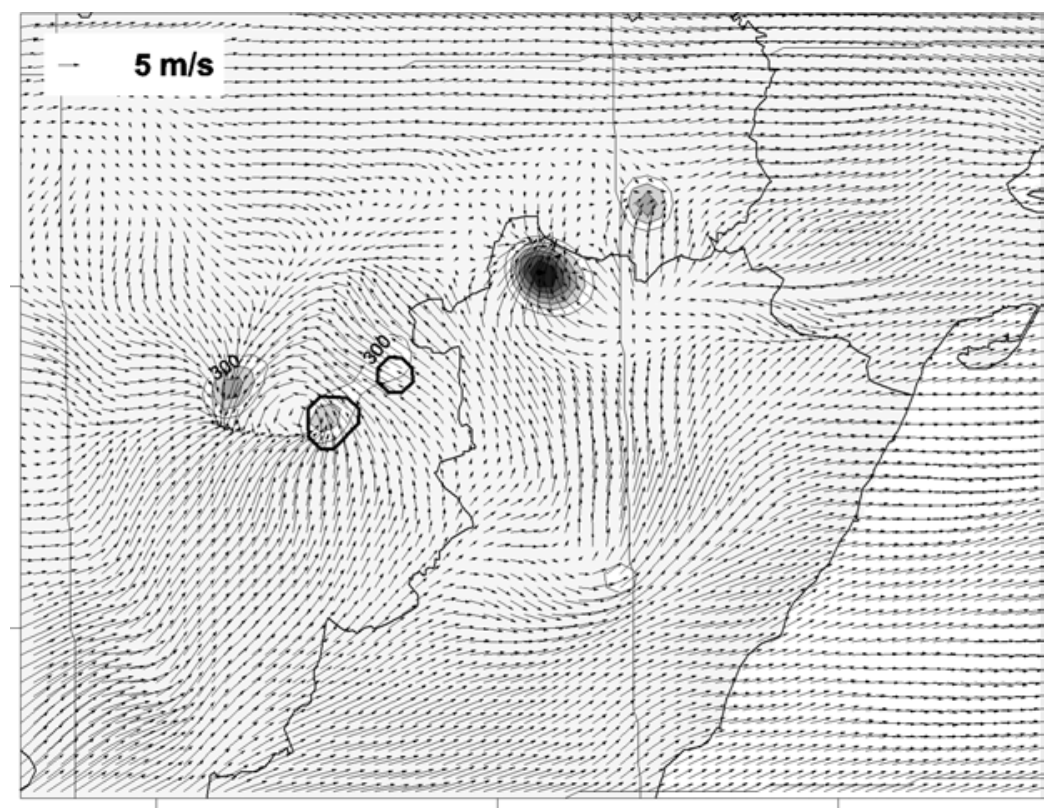

Fig. 9. Horizontal wind $\left(\mathrm{m} \mathrm{s}^{-1}\right)$ at $800 \mathrm{hPa}$ and upward velocity ( $\mathrm{cm} \mathrm{s}^{-1}$, shaded) at $500 \mathrm{hPa}$ for the control run at 1730 UTC. Contour interval is $300 \mathrm{~cm} / \mathrm{s}$. Areas with non-zero STORM parameter are bounded with strong solid line. A zoom over the area of interest is made to appreciate the full $2 \mathrm{~km}$ wind field details

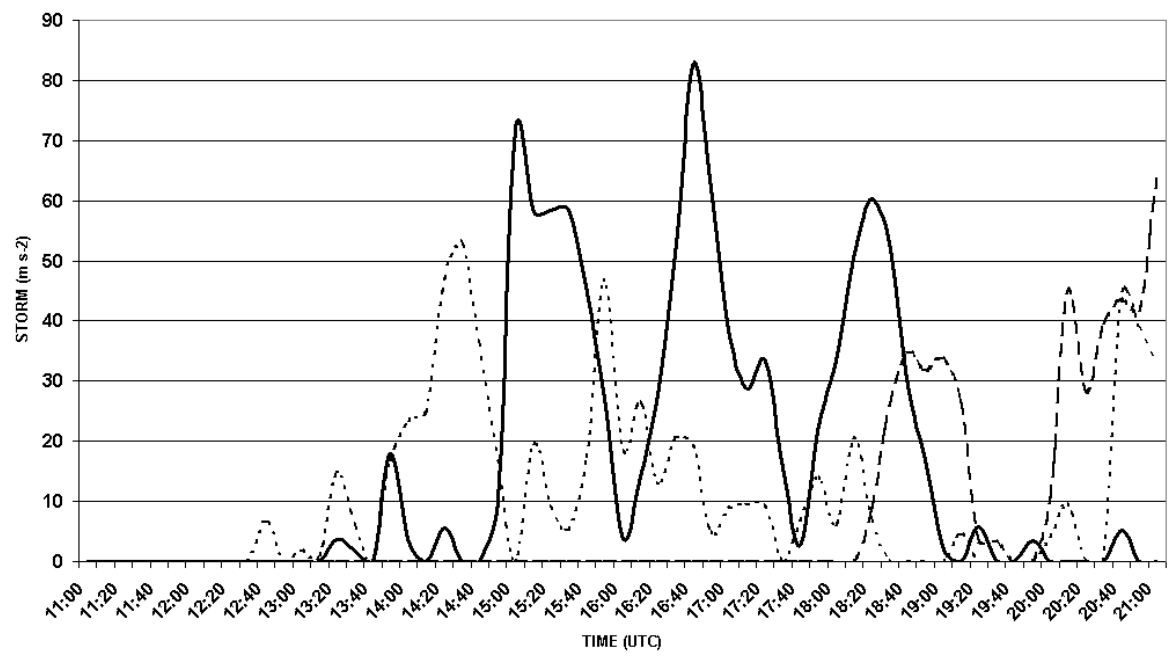

Fig. 10. Evolution of the STORM parameter for the control (solid), no radiation (dashed) and smooth orography (dotted) simulations. Note that the no orographic simulation does not fullfil the STORM conditions at any time. 


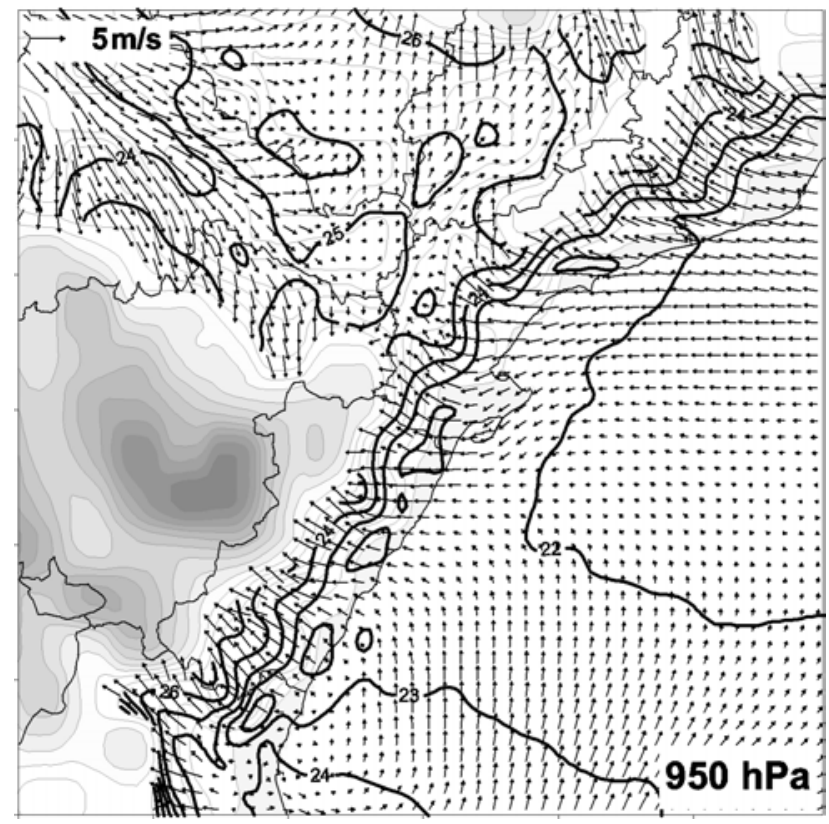

a

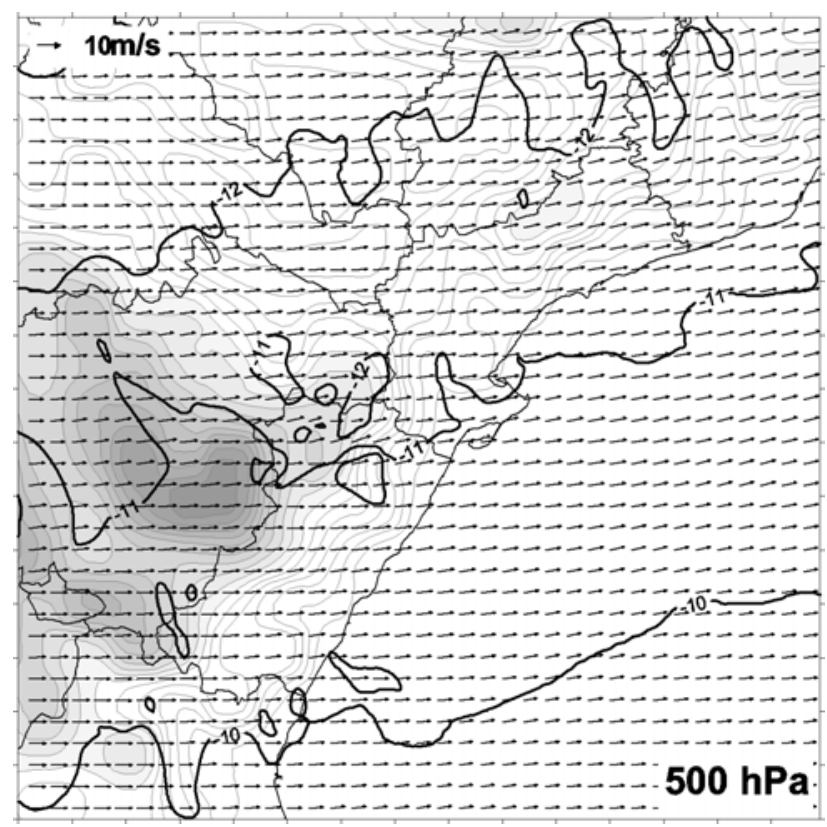

c

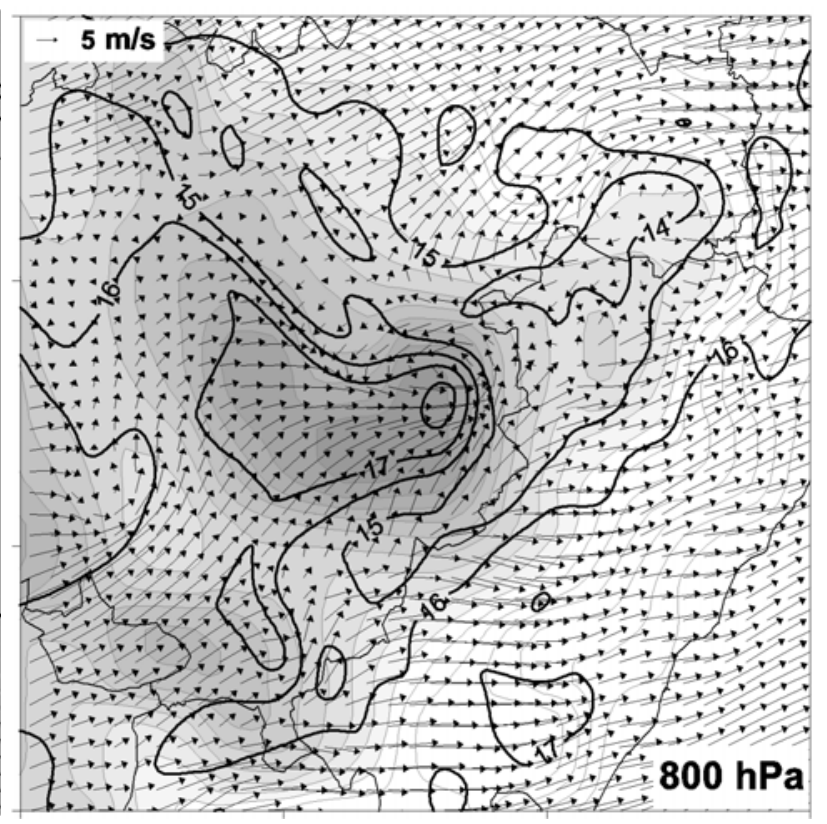

b

Fig. 11. Mid and low levels mesoscale situation at 1300 UTC for the smoothed orography run. Horizontal wind $\left(\mathrm{m} \mathrm{s}^{-1}\right)$ and temperature $\left({ }^{\circ} \mathrm{C}\right)$ at a) $950 \mathrm{hPa}$, only above ground level. b) $800 \mathrm{hPa}$. c) $500 \mathrm{hPa}$. Note the larger zoom applied to panel $\mathrm{b}$ than to panels a and c. Topography (100 m interval) as well as administrative boundaries are depicted for easy geographical reference. 


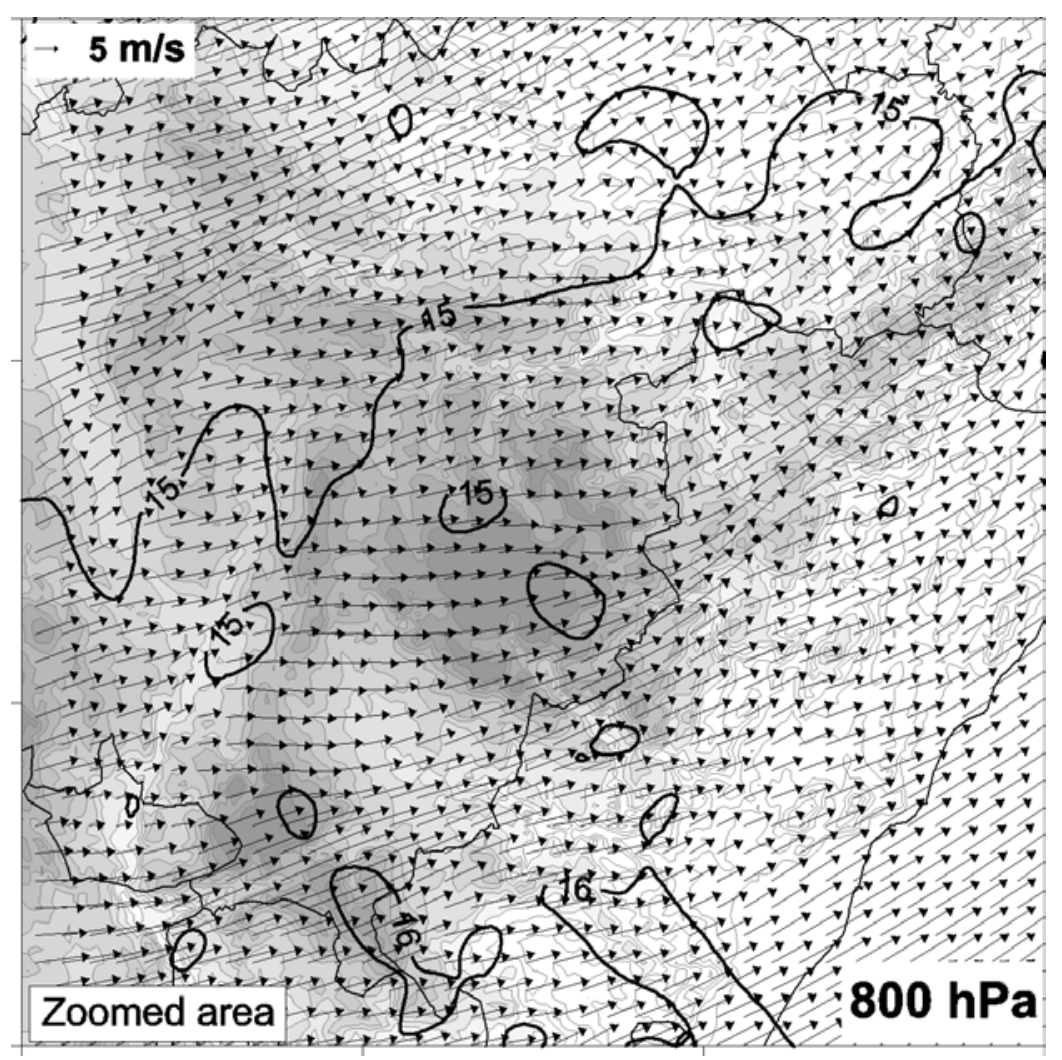

Fig. 12. As in Fig. 11b but for the no solar radiation run. 